\title{
WEBINAR BASED CROSSBORDER TRAINING INITIATIVE BY CEOS WGCapD ON SAR AND DISASTERS: ACHIEVEMENTS AND LESSONS LEARNT
}

\author{
A.Senthil Kumar ${ }^{1 *}$, H. Ferrera ${ }^{2}$, S.P. Aggarwal ${ }^{1}$, E.C. Wood $^{3}$ \\ ${ }^{1}$ Centre for Space Science and Technology Education in Asia and the Pacific, Dehradun 248001 India - (senthil, spa)@iirs.gov.in \\ ${ }^{2}$ INPE-National Institute for Space Research, São José dos Campos, 1758, 12227-010 São José dos Campos (SP) Brasil \\ ${ }^{3}$ Center for Earth Resources Observation and Science, U.S. Geological Survey, Sioux Falls, SD 57198 USA
}

Commission V, WG V/6

KEY WORDS: Face-to-face learning, Distance learning, Moodle

\begin{abstract}
With the utilisation of earth observation satellite data for various national and regional resources management programs, there has been tremendous interest in learning the status of current technology and sources of data and services availability amongst the students and working professionals across the globe. Often, face-to-face training may face difficulty in getting subject experts due to increased restriction of international travel and time. Webinars come as a big relief for such programs to bring together the right speakers and participants from all over the globe. In this paper, we describe two such webinar series one on disaster management and the other on synthetic aperture radar and its applications, initiated by working group on capacity building and data democracy of CEOS. The overall participants' feedback of these webinars are satisfactorily, and lessons learnt for further scope of such webinar series is brought out.
\end{abstract}

\section{INTRODUCTION}

Crossborder education deals with means and ways of such transnational sharing of knowledge (Knight, 2006). There are many formats to crossborder education: Vocational or summer school face to face training, theme based webinars, regular elearning, tutorials in Symposia or conferences, joint education programs or off-shore training are some of many ways of exploring the cross border education.

Often, face-to-face training may face difficulty of getting subject experts whose programs do change dynamically. The second important reason is the increased restriction of funds to meet international travel expenses and accommodation charges. With increased use of information technologies, high speed internet becomes a reality in most part of the globe. This permits one to consider promoting web-based resources sharing of both human expertise and training/education tools and material for effective learning without in-person or face-to-face training approach. This despites geographical time differences across the nations, thus becoming a powerful method of knowledge sharing under cross-border education process.

Interestingly, many subject experts prefer to address the participants through Skype, go-to-webinar or go-to-meeting or equivalent such web-service portals available today without any subscription for this purpose. There are also many virtual laboratories, demonstrations available online today in subjects connected to Geoinformation Technologies and their applications, which can be used as study material for practical purposes though educator is far apart (IIRS, 2018; GODAN, 2018; ARSET, 2016). A constraint to this mode often faced is the geographical time difference between the speaker's country and the wide audience from different countries cutting across the globe.

\footnotetext{
${ }^{*}$ Corresponding author
}

The webinar mode is one kind of distance learning programmes where best faculty can be invited from different concerned organizations or agencies in the world. Also, it can cover entire world and participants can join these lectures sitting at their workplace or home. All the lectures can be recorded to place in a learning management system (LMS) typically built for such programs. Participants can watch even after webinar time. Webinar saves our time and money. This is truly a teaching method for covering entire globe. There are many successful stories to webinar series of knowledge transfer across the global user community.

In this paper, we describe about two different theme-oriented webinar series unique of their kind conducted by Working Group on Capacity building and Data Democracy (WGCapD) of the Committee on Earth observation Satellites (CEOS). These series attracted large students and working professionals across the globe. One was on Remote Sensing Technology for disaster management during April 6 to May 31, 2016 and second was on SAR data processing and Applications during April 17 to June 9, 2017. These two webinars are described in detail along with feedback received from the users. Before this, we describe briefly on the objectives of WGCapD in following section.

For more details on its activities and programs, the reader may visit: http://ceos.org/ourwork/workinggroups/wgcapd/

\section{WGCapD AND ITS ACTIVITIES}

With increased utilization of Earth observation satellites data for actionable products and services enabling us from national and regional development programs to palm-held navigational devices, it becomes mandate to raise awareness of the value of Earth Observation (EO) data products and services to user communities, including support to locate and access data, products and tools. Realizing the importance of this, the Committee on Earth Observation Satellites (CEOS) has formulated in 2011 a new working group on Capacity Building 
and Data Democracy (WGCapD). The prime objective of this working group is to undertake a variety of activities to promote under four pillars. Firstly, it is to provide wider and easier access to Earth Observation data. Secondly, increasing the sharing of software tools such as the use of open source software and open systems interface is to be popularised among the user community. Thirdly, this group aims to enhance data dissemination capabilities and transferring relevant technologies to end users. Lastly, it undertakes intensive capacity building, education, and training (including awareness and outreach) for enabling end users to gather the information they need and for increasing communication on achieved results.

To supplement the above, the WGCapD works on programs to support CEOS new initiatives and help other working groups and virtual constellations undertake their own capacity building initiatives, e.g., with a set of best practices guidance. In addition, WGCapD collaborate with GEO, UNOOSA and other UN agencies in many global gatherings in bringing out the benefits of EO tools and services, in providing help to collect, coordinate and synchronize $\mathrm{CB}$ resources, and provide expertise to support their efforts in workshops, symposia and conferences.

To achieve these objectives, WGCapD organizes various activities, which includes training programmes, workshop at various locations. One of the recent initiatives is to promote webinar series on the prime subject of interest for larger audience. Two of these series conducted are explained in detail along with feedback received and lessons learnt.

\section{WEBINAR SERIES OF WGCAPD}

\subsection{Remote Sensing Technology for disaster management}

This webinar has the linkage to the fact that many space agencies have initiated a series of actions to support disaster risk management, DRM, more efficiently, with a focus on Disasters Risk Reduction (DRR), by optimizing and better coordinating satellite Earth observations (WGCapD, 2015). While improvements to the International Charter or Sentinel Asia, for example, can offer an enhanced post-crisis support, it is critical that space agencies invest in disaster preparedness and prevention. In view of this WGCapD has organized its first webinar series during April 6 to May 312016.

This webinar series consisted of a series of introductory webinars that addressed the use of remote sensing technology for the DRM. The space agencies, INPE and ISRO proposed the preliminary syllabus and the course structure as well as interested CEOS Agencies provided points of contact to be potential instructors for the course. A core team (INPE, ISRO, ESA, NOAA, USGS and NASA SEO) was set up and held several teleconferences to finalise the training programs.

In March 2015, the course was widely advertised through CEOS website (http://www.ceos.org), CEOS lists, WMO-CGMS Virtual Laboratory for Education and Training in Satellite Meteorology (VLab) newsletter, INPE mailing list, ISU mailing list, CSSTEAP mailing list, AfriGEOSS mailing list and a special list of ex-students. Social media such as Facebook and Twitter were also used. The methodology of this course was based on the online distance education principles that allow participants to fully engage with program content, their peers, and their instructors via live lectures, question/answer through discussion forums and feedback mechanisms. For self-assessment purposes, brief quizzes were available after each webinar.

Course materials included well-organized presentations, selected datasets and internet links. Using INPE's license to go-to- webinar web portal, one live classroom session per week was held, recorded and made available for downloading. Students received exposures to a variety of resources, software tools and datasets, all of open and free access.

Moodle, acronym for modular object-oriented dynamic learning environment, was used for the course administration, documentation, tracking, reporting and delivery system. It was hosted at the National Institute for Space Research - INPE (Moodle Learning Platform) Also, it was used to support the course fostering the interaction among instructors and students with different backgrounds.

The thirteen instructor volunteers came from five CEOS Members and Associates (INPE, ISRO, NASA, ESA and USGS) and universities and training centers such as University of Waterloo (Canada), International Space University (ISU) and NASA ARSET (Applied Remote Sensing Training).

Topic covered in eight lectures by webinars are listed below.

a) Introduction to Webinars Series: Overview of CEOS/WGCapD, Where CEOS can help: Datasets and Useful Tools: CEOS Visualization and Environment (COVE), the CEOS Earth Observation Handbook, International Collaboration for DRM: International Charter for Space and Major Disasters. Instructors: INPE, CEOS, USGS

b) Introduction to Disasters: Causes, effects, monitoring, mitigation, and management. Methods of hazard, vulnerability, and risk assessment and the role of geospatial data. Instructor: Univ. of Waterloo, ISU

c) Space-based Earth observation systems and their applications for hydro-meteorological disasters (floods). Instructors: ISRO, NASA

d) Space-based Earth observation systems and their applications for geological disasters (earthquakes, landslides, and volcanoes): Instructor: ESA

e) Space-based Earth observation systems for environmental disasters (forest fires) - Instructor: INPE

f) Real Time Monitoring of Global Precipitation from Space: New Technologies Applied to Heavy Rainfall Risk Reduction: Instructor: INPE

g) Concepts and applications of internet GIS and Sensor Web (network of sensors) for disaster management. Example of an open source tool (TerraMA2 computational platform for developing Monitoring, Analysis and Alert systems). Instructor: INPE

h) Rapid mapping and emergency services: Success stories - International Charter for Space and Major Disasters: Instructor: USGS

There were many unique benefits to the participants of this webinar. It was offered free of charge access to expertise from space agencies around the world. Participants were linked to a global network of experts and policymakers, created awareness about international coordination bodies, such as CEOS, Group on Earth Observations (GEO), United Nations Office for Outer Space Affairs (UNOOSA), and the International Charter for 
Space and Major Disasters and Provided access to datasets and useful tools available from CEOS Members Built skills on Disaster Management (DM).

The course was open to participants from all countries. The target audience focused on Disaster Management practitioners with an interest in geospatial technology. However, one prerequisite was addressed. Elementary knowledge about Remote Sensing, Geographic Information Systems (GIS) and Digital Image Processing.

We have received 144 registrations and could only accept 99 participants due technical restrictions (limitation of Go-ToWebinars portal for free connection). The selection was made on the first came and first serve bases, and the geographic distribution by continents is showed in Figure 1. All 99 students selected have had, at least, a bachelor degree in wide variety of areas, for instance, Geography, Science, Engineering, Agronomy, Geology, Physics, Hydrology, Computer Science, Meteorology, among others. 42 of them held the Master of Science degree 11 are PhDs. Students' affiliations include universities, United Nations Regional Centers, Regional Centers, Government, Private Sector and NGOs.

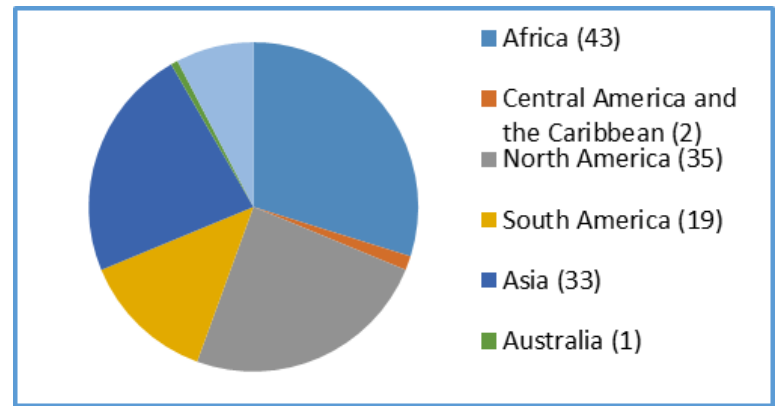

Figure 1 - Geographic distribution of all 144 registrants

Considering the results of our surveys (Figure 2), most of the students were satisfied with their learning and very grateful for the opportunity. However, Hands on experience should be strengthen in such type of distance learning course.

In order to have some specific feedback from the students, there was an open question in the survey: Which parts of the course did you find most/least helpful? The answers are summarized in Table 1 .

\section{Lesson learned}

Overall, this has been a successful multicultural experience for accessing education in Remote Sensing. The course has contributed to achieve or at least to start the path towards realizing the goals:

- Create awareness about international coordination bodies, such as CEOS, Group on Earth Observations (GEO) and the International Charter for Space and Major Disasters as major sources of data for DRM.
Indicate your level of agreement with this statement: This course met my expectations.

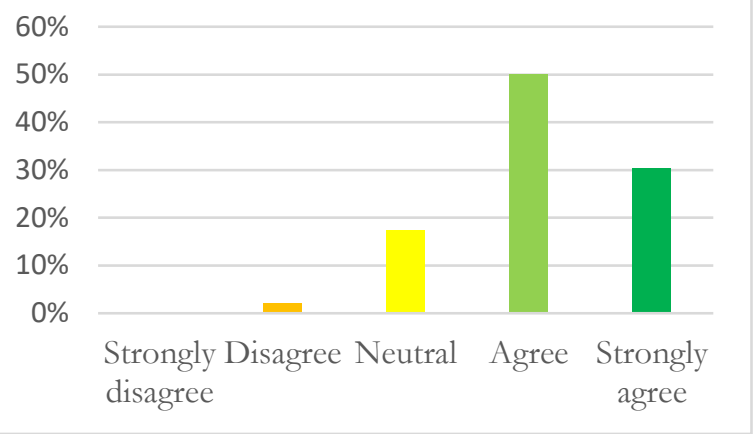

Indicate your level of agreement with this statement: This course increased my level of interest in the subject.

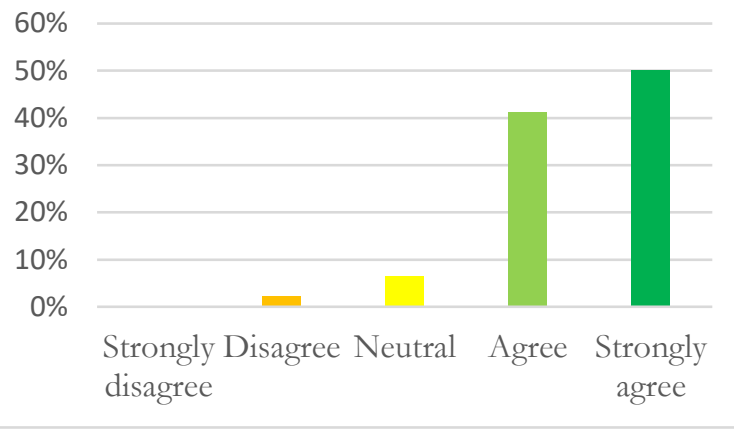

Figure 2. Level of satisfaction on Expectations and Subject Interest of participants

- Learn about data availability through the International Disaster Charter during a disaster and how this body could be activated.

- Learn the role of data dissemination systems (e.g. GEONETCast and other system) to effectively reach areas of lack consistent internet access or redundant system in case of emergencies.

- Learn how to utilize satellite data (EO) from different sources in the case of DRM.

- Be able to determine which specific GIS capabilities and kinds of data are required to support emergency management work before, during and post disaster.

- Be able to support decision makers as advisor, learning how to use the space technology in DRM.

- Use appropriate techniques, software and procedures in order to achieve the objectives.

- Establish new contacts with other professionals worldwide. 


\begin{tabular}{|l|l|}
\hline \multicolumn{1}{|c|}{ Most helpful } & \multicolumn{1}{|c|}{ Least Helpful } \\
\hline All, the whole course was so informative. & None, all of them were very helpful \\
\hline $\begin{array}{l}\text { The review of the types of data publicly available. Some } \\
\text { ideas on how to get it and how to use it. I have appreciated } \\
\text { this opportunity. }\end{array}$ & $\begin{array}{l}\text { The quizzes were an ok form of self-assessment. However, } \\
\text { I didn't like having to wait to get the correct answers. }\end{array}$ \\
\hline $\begin{array}{l}\text { The experience of the instructors and the exchange of } \\
\text { contacts with the other participants. }\end{array}$ & $\begin{array}{l}\text { Just to say there were not African examples of studies } \\
\text { applicable to Africa. }\end{array}$ \\
\hline $\begin{array}{l}\text { Presentations on hydro-meteorological and geological } \\
\text { disasters was extremely informative. }\end{array}$ & \\
\hline $\begin{array}{l}\text { I find most helpful the parts of the course that give us } \\
\text { information about access of data. }\end{array}$ & \\
\hline The recordings. & \\
\hline The case studies. & $\begin{array}{l}\text { The explanations of the experts when giving the } \\
\text { presentation. }\end{array}$ \\
\hline $\begin{array}{l}\text { The explanation of the different platforms using remote } \\
\text { sensing and satellite imagery. }\end{array}$ & \\
\hline $\begin{array}{l}\text { The last module on International Space Charter was of } \\
\text { great interest to me. }\end{array}$ & \\
\hline Modules 3, 5 and 6 were the most useful modules & \\
\hline
\end{tabular}

Table 1. Feedback on the Most \& Least Helpful part of the Webinar

\subsection{SAR Data Processing and Applications}

Synthetic Aperture Radar (SAR) remote sensing provides a new dimension for measuring various bio-geophysical parameters of the features on Earth surface. SAR sensors are advantageous in comparison to optical remote sensing because of their day night capabilities and penetration to even dense cloud cover. SAR polarimetry (PolSAR) and Polarimetric SAR Interferometry (Pol-InSAR) are widely used techniques, which exploit polarimetric and interferometric properties of various man-made and natural scatterers in order to extract the qualitative and quantitative physical information about land, ocean and snow.

The growing interest of SAR remote sensing community in retrieval of 3-dimensional information of earth objects makes both polarimetric SAR interferometry and SAR tomography as hot topics in recent years. It is expected that combining these two techniques (PolTomSAR) would provide much better discriminating ability for scatterers lying in the same pixel. Generally, this is about reconstruction of scattering profiles from limited and irregular polarimetric measurements.
Scientific community is making untiring efforts to resolve the problem of complexity in advance processing of SAR data for different applications through training, education and research. Current research works on SAR remote sensing involve PolSAR, PolInSAR, Differential SAR Interferometry (DInSAR) and PolTomSAR for the manmade and natural objects appearing on Earth surface.

The Webinar series was organized again with 8 topics (WGCapD, 2017). The faculty are highly experienced Scientists/ faculty from ISRO, NASA, ESA, DLR and Agrifood Canada. The details are given in Table 2.

Total 252 participants from 53 countries attended the webinar series across the globe. Noting the limitation set by go-towebinar software usage in free-of-cost mode, effort has been made to enhance the participants by paying mandatory charges to go-to-webinar webmaster. However, it was observed that all the participants have not attended all the 8 webinars. They have attended as per their interest. The participants were mostly professionals working in Government and private industries. We have also received good participation from women (Figure 4).

\begin{tabular}{|l|l|l|c|}
\hline S. No. & Title of the lecture & Learning Objective & Instructor Agency \\
\hline W1 & $\begin{array}{l}\text { Overview of SAR } \\
\text { Remote Sensing }\end{array}$ & $\begin{array}{l}\text { Principles of Microwave Remote Sensing - covering } \\
\text { Microwave Bands, Imaging Radar Geometry, Synthetic } \\
\text { Aperture Radar (SAR), SAR versus other Earth Observation } \\
\text { Instruments, Definition of SAR Resolutions, Applications of } \\
\text { SAR Remote Sensing }\end{array}$ & ISRO \\
\hline W2 & $\begin{array}{l}\text { SAR Data Format, } \\
\text { SAR Missions and } \\
\text { data access }\end{array}$ & $\begin{array}{l}\text { Different types of SAR systems - covering platforms and } \\
\text { operating modes of data acquisitions, data formats from raw } \\
\text { to geocoded processing, SAR missions, SAR data access }\end{array}$ & ESA \\
\hline W3 & SAR data processing & $\begin{array}{l}\text { Different Levels of SAR Data processing - covering raw data } \\
\text { to calibrated products and speckle reduction to improve the } \\
\text { visual image quality. }\end{array}$ & ISRO \\
\hline W4 & $\begin{array}{l}\text { Basics of SAR } \\
\text { Polarimetry and } \\
\text { Interferometry }\end{array}$ & $\begin{array}{l}\text { Polarimetric SAR Remote Sensing - covering basic } \\
\text { principles and scattering matrices for image modeling, 3-D } \\
\text { mapping and contouring. }\end{array}$ & ISRO \\
\hline
\end{tabular}




\begin{tabular}{|l|l|l|c|}
\hline W5 & $\begin{array}{l}\text { SAR Remote Sensing } \\
\text { for Geological } \\
\text { Applications }\end{array}$ & $\begin{array}{l}\text { Terrain Mapping and Analysis, Differential Interferometry } \\
\text { for Landslide and Land Subsidence Monitoring }\end{array}$ & ISRO \\
\hline W6 & $\begin{array}{l}\text { SAR Remote Sensing } \\
\text { for Forest, crop and } \\
\text { soil moisture }\end{array}$ & $\begin{array}{l}\text { Need and Requirement of SAR for Forest Biophysical } \\
\text { Parameter Assessment, Crop mapping and monitoring and } \\
\text { soil moisture estimation }\end{array}$ & $\begin{array}{l}\text { ISRO, Agriculture \& } \\
\text { Agrifood, Canada }\end{array}$ \\
\hline W7 & $\begin{array}{l}\text { PolSAR and InSAR } \\
\text { Applications in Snow } \\
\text { and Glacier Studies }\end{array}$ & $\begin{array}{l}\text { Retrieval of Snow Cover Area (SCA),Snow Physical } \\
\text { Parameters, Glacier Dynamics, Ice Sheet and Sea ice } \\
\text { Dynamics }\end{array}$ & DLR, ISRO \\
\hline W8 & $\begin{array}{l}\text { SAR data for Flood } \\
\text { Mapping }\end{array}$ & $\begin{array}{l}\text { SAR Remote Sensing for flood inundation mapping and } \\
\text { monitoring }\end{array}$ & ESA, NASA \\
\hline
\end{tabular}

Table 2. Details of SAR webinar - its learning objectives and space agencies involved.

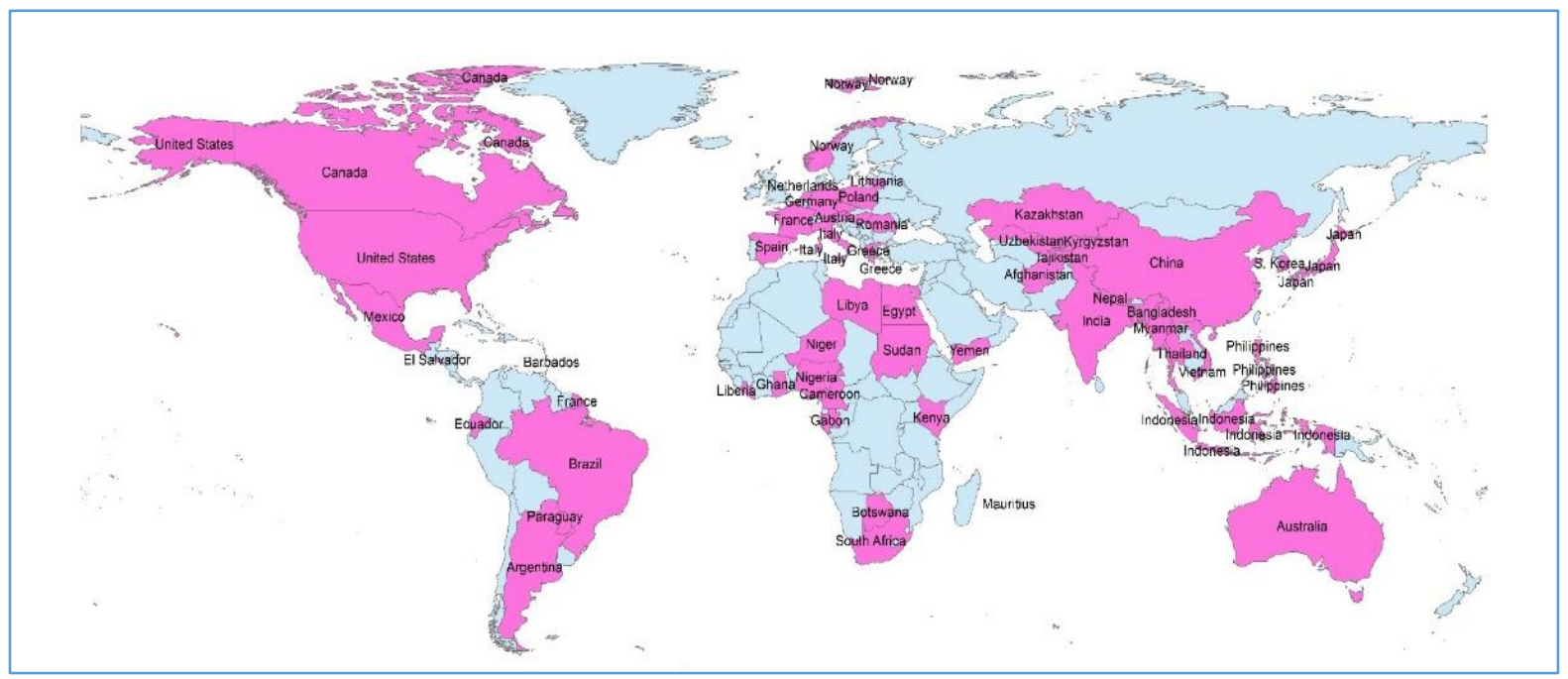

Figure 3. Geographical distribution of 252 participants in SAR Webinar 2017.

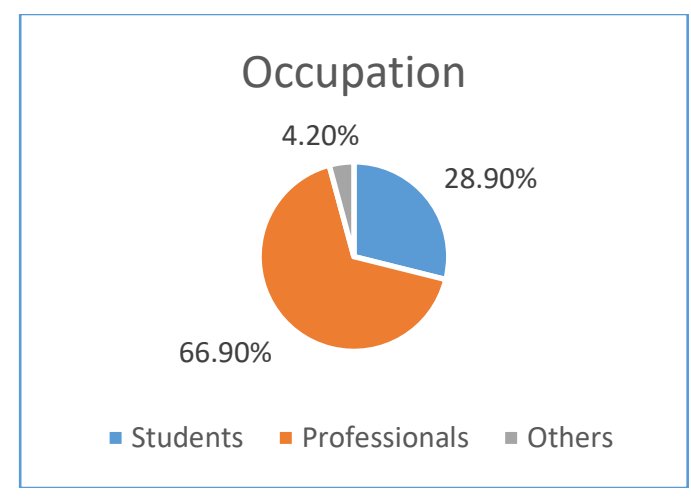

Mail/ Female Ratio

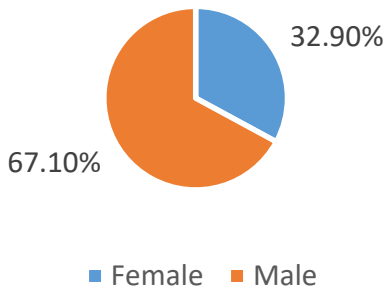

Figure 4. Occupation of participants and male-female participation ratio

\section{Lesson learned}

Following are important lessons learnt for plan of action while conducting the webinar series.

- About $90 \%$ participants have rated this webinar as very good to excellent;

- More emphasis on hands on exercises

- Case studies should be from different regions

- Requirements of capacity building are different from one region to another region.

- Participants were very keen to have more such webinars on different themes such as UAV Technology \& its applications, Lidar Technology \& its applications, Hyperspectral remote sensing and its applications in various fields, Natural Resources Management (hydrology, forest, agriculture), Urban Mapping, monitoring and planning, Disaster monitoring and damage assessment, Air Quality monitoring, Advances in RS and GIS and alike.

\section{CONCLUDING REMARKS}

Webinars have become viable tool for conducting global training of importance for space-based solutions to sustainable development programs. The main advantage with the webinar lecturing is that subject experts readily 
accept such proposal as there is no constraint on time and cost involved as with face-to-face training. With advantage of high-speed internet facilities, the live transmission, sharing videos and conducting practical classes have become possible. The recent webinar on synthetic aperture radar has attracted many mid-career professionals across the globe, thus encouraging to plan such advanced courses in geoinformation technologies and applications.

\section{ACKNOWLEDGMENT}

Comments and suggestions received from anonymous reviewer are sincerely acknowledged with thanks.

\section{REFERENCES}

ARSET, 2018. NASA Applied Remote Sensing Training Webinar Series, https://arset.gfsc.nasa.gov.

GODAN, 2018. Webinar series. https://www.cta.int

IIRS (Indian Institute of Remote Sensing), 2018. IIRS-ISRO

Outreach Programme. https://elearning.iirs.gov.in
Knight, J. 2006. Higher education crossing borders: A Guide to the implications of the General Agreement on Trade in Services for Cross-border Education, Commonwealth of Learning, Columbia, Canada.

WGCapD, 2015. Distance Education Course: Remote Sensing Technology for Disaster Management.

http://ceos.org/meetings/wgcapd-distance-education-2015/

WGCapD, 2017. SAR Data Processing and Applications http://ceos.org/meetings/wgcapd-sar-webinar/ 